\title{
Incidentally Detected Amyloid Light-Chain Amyloidosis Caused by Monoclonal Gammopathy of Undetermined Significance: Possible Time-Dependent Change in Colonic Findings
}

\author{
Toshiro Fukui Yuji Tanimura Yasushi Matsumoto Shunsuke Horitani \\ Takashi Tomiyama Kazuichi Okazaki \\ Division of Gastroenterology and Hepatology, Third Department of Internal Medicine, \\ Kansai Medical University, Hirakata, Hirakata, Japan
}

\section{Keywords}

Gastrointestinal amyloidosis · Fecal occult blood test · Colonoscopy · Amyloid light-chain amyloidosis · Monoclonal gammopathy of undetermined significance
Abstract
Amyloid light-chain (AL) amyloidosis is associated with plasma cell disorder and monoclonal light chains. This type of amyloidosis is the prominent type involving the gastrointestinal tract. Monoclonal gammopathy of undetermined significance (MGUS) is the most common plasma cell disorder and a known precursor of more serious diseases. A 72-year-old male was treated for high blood pressure, diabetes, and gout at the clinic of a private physician. Due to a positive fecal occult blood test discovered during colon cancer screening, he underwent colonoscopy and was diagnosed with adenomatous polyps by biopsies. Two months later, he was referred 


\section{Case Reports in Gastroenterology}

Case Rep Gastroenterol 2018;12:737-746

DOI: $10.1159 / 000494919$

(c) 2018 The Author(s). Published by S. Karger AG, Basel www.karger.com/crg

Fukui et al.: Colonic Findings of Amyloid Light-Chain Amyloidosis

to our hospital for endoscopic resection of the polyps. Although the polyps were successfully removed, a colonoscopy revealed two types of ulcerative lesions. Immunohistopathological evaluations obtained from these lesions and polyps confirmed amyloid deposition. Although esophagogastroduodenoscopy results were normal, a biopsy specimen from the patient's stomach showed the same type of amyloid deposition. Immunoelectrophoresis showed Mproteins for anti-IgG- $\lambda$ in the serum and $\lambda$ type Bence-Jones protein in the urine. His blood, bone marrow, and urine test results led to a diagnosis of MGUS. A coronary angiography revealed multivessel stenosis, and the patient's cardiac function improved after coronary artery stenting. Hereafter, a combination therapy with bortezomib, lenalidomide, and dexamethasone is planned. This is a case report of systemic AL amyloidosis caused by MGUS, which was incidentally detected by colonoscopy.

(C) 2018 The Author(s)

Published by S. Karger AG, Basel

\section{Introduction}

Amyloidosis is a protein-conformational disease caused by the misfolding and aggregation of autologous protein. This protein deposits in tissues as amyloid fibrils and ultimately leads to organ architecture disruption and dysfunction. Amyloid light-chain (AL) amyloidosis is the most common form of systemic amyloidosis. AL amyloidosis is associated with plasma cell disorder and monoclonal light chains in serum and/or urine. Fifteen percent of patients with AL amyloidosis have multiple myeloma, although symptomatic myeloma is unusual [1]. This type of amyloidosis is the prominent type involving the gastrointestinal (GI) tract. Treatment of amyloidosis is type dependent; thus, quickly reaching a diagnosis of amyloidosis and confirming its correct type are critical. At present, the overall 4-year survival rate of patients with AL amyloidosis ranges from 40 to $60 \%$. In addition, early mortality was observed resulting from advanced cardiac damage, with approximately $30 \%$ of the patients dying within 1 year from diagnosis [2-4].

Monoclonal gammopathy of undetermined significance (MGUS) is the most common plasma cell disorder, and the prevalence of MGUS increases with age, from $1.7 \%$ in patients aged 50-59 years to more than $6.6 \%$ in patients aged 80 years and older [5]. MGUS is an asymptomatic premalignant disorder, defined by a serum monoclonal immunoglobulin concentration of $<3 \mathrm{~g} / \mathrm{dL}$ and a proportion of plasma cells in the bone marrow of $<10 \%$ in the absence of lytic bone lesions, anemia, hypercalcemia, and renal insufficiency related to the proliferation of monoclonal plasma cells. MGUS is a known precursor of more serious diseases, such as multiple myeloma, AL amyloidosis, and Waldenström macroglobulinemia; however, most patients with MGUS do not develop a plasma cell malignancy [6]. The screening test for MGUS, serum protein electrophoresis, is commonly performed in patients presenting with a wide variety of clinical symptoms. Identifying true disease associations with MGUS is of major importance because it sheds light on the pathogenesis of both MGUS and the associated disorders.

The GI tract is a common site of amyloid deposition; therefore, GI involvement is common in systemic amyloidosis, while localized GI amyloidosis is rare [7]. However, only $30-60 \%$ of the affected individuals develop GI symptoms from the disease [1]. The nonspecific and vague nature of symptoms associated with different forms of amyloidosis frequently leads to delays 


\section{Case Reports in Gastroenterology}

Case Rep Gastroenterol 2018;12:737-746

DOI: $10.1159 / 000494919$

(c) 2018 The Author(s). Published by S. Karger AG, Basel www.karger.com/crg

Fukui et al.: Colonic Findings of Amyloid Light-Chain Amyloidosis

in diagnosis when organ dysfunction is already advanced. Although GI symptoms include macroglossia, dysphagia, abdominal pain, hemorrhage, constipation, diarrhea, and malabsorption, patterns of amyloid deposition are associated with different clinical and endoscopic features $[8,9]$. Amyloid deposition in the muscularis mucosae, submucosa, muscularis propria and their vessel walls is dominant in AL amyloidosis and leads to polypoid protrusions, submucosal tumor-like lesions, submucosal hematomas, ulcers, and thickening of the valvulae conniventes. Granular amyloid deposition mainly in the propria mucosae has been related to amyloid A (AA) amyloidosis, resulting in a fine granular appearance, vascular growth, mucosal friability, and erosions $[7,8,10]$. As a result, AL amyloidosis usually presents with constipation, mechanical obstruction, or chronic intestinal pseudo-obstruction, while AA amyloidosis presents with diarrhea and malabsorption [8].

\section{Case Presentation}

A 72-year-old male with hypertension, diabetes mellitus, and gout was being treated by a physician in a private practice. Although the patient had no specific symptoms, he underwent a fecal occult blood testing in colon cancer screening. The test was positive, and he was further examined by colonoscopy. Some adenomatous polyps were diagnosed by biopsies; however, there were no other abnormal endoscopic findings in his colon. Two months after the initial colonoscopy, he was referred to our department for the treatment of his polyps. As expected, known polyps were successfully resected by endoscopic mucosal resection. However, there were two unexpected ulcerative lesions in his transverse colon; one was an irregularly shaped ulcer with submucosal hematoma (Fig. 1a, b), and the other was a sharply marginated ulcer with slight submucosal hematoma (Fig. 1c, d). Histological examinations of biopsy specimens of these lesions and the endoscopically resected polyps revealed deposition of eosinophilic, homogeneous, and amorphous material mainly in the submucosal blood vessel walls of the colon using hematoxylin-eosin staining (Fig. 2a) and Congo red (Fig. 2b). Immunohistochemically, the deposits were positive for amyloid P (Fig. 2c) and $\lambda$ light chain (Fig. 2d), and negative for AA (Fig. 2e) and $\kappa$ light chain (Fig. 2f), indicating $\lambda$-light-chain restriction. Although an esophagogastroduodenoscopy showed no abnormal findings, the same kind of deposits was also found mainly in the mucosal stroma and blood vessel walls of biopsy specimens of the stomach (Fig. 2g), which were positive for Congo red (Fig. 2h), amyloid P (Fig. 2i), and $\lambda$ light chain (Fig. 2j), and negative for AA (Fig. 2k) and $\kappa$ light chain (Fig. 2l). The direct Fast Scarlet stained the deposits an orange-red color (data not shown). To investigate the cause and progression of his amyloidosis minutely, we specifically examined his blood, bone marrow (Fig. 3 ), and urine (Table 1). Immunofixation electrophoresis showed M-proteins for anti-IgG- $\lambda$ in the serum and $\lambda$-type Bence-Jones protein in the urine. A serum-free light-chain assay indicated a decreased $\kappa$ chain, an elevated $\lambda$ chain, and an abnormal $\kappa / \lambda$ ratio. According to "Diagnostic criteria for plasma cell disorders" [11], he was diagnosed as having non-IgM (IgG- $\lambda$ ) MGUS. Using this information, we made a definitive diagnosis of systemic AL amyloidosis caused by MGUS. ${ }^{18 \mathrm{~F}-F l u o r o d e o x y g l u c o s e}$ positron emission tomography/computed tomography showed no abnormal ${ }^{18} \mathrm{~F}$-Fluorodeoxyglucose uptake anywhere in his body.

Abnormally high levels of $\mathrm{N}$-terminal pro-brain natriuretic peptide and thyroid-stimulating hormone and a low level of free thyroxin were suspected to be potential abnormal values 


\section{Case Reports in Gastroenterology}

Case Rep Gastroenterol 2018;12:737-746

DOI: $10.1159 / 000494919$

(c) 2018 The Author(s). Published by S. Karger AG, Basel www.karger.com/crg

Fukui et al.: Colonic Findings of Amyloid Light-Chain Amyloidosis

of his amyloidosis. Although he had no cardiac manifestations at that point, the patient's low ejection fraction (48\%) was confirmed by echocardiography, and a coronary angiography revealed multivessel stenosis. After the patient underwent coronary artery stenting, his cardiac function is gradually improving. Hereafter, a combination therapy with bortezomib, lenalidomide, and dexamethasone for MGUS is planned, but we will strictly monitor his condition and carefully determine indications for treatment.

\section{Discussion}

We describe a case of systemic AL amyloidosis caused by MGUS, which was incidentally recognized at the time of endoscopic resection of the patient's colon polyps. A fecal occult blood test used in colon cancer screening led to the early detection of the patient's disorder. Two months before detection, there were no endoscopic findings of amyloidosis in his colon. Presumably, during this brief period, the colonic ulcerative lesions developed rapidly. In addition, one lesion was an irregularly shaped ulcer with submucosal hematoma, and the other was a sharply marginated ulcer with slight submucosal hematoma. These findings potentially reflect the time-dependent change and healing process of ulcerative intestinal lesions of $\mathrm{AL}$ amyloidosis. The endoscopic findings of ulcer and submucosal hematoma observed in the colon of this patient are characteristic of AL amyloidosis, as described above [8, 9]. Submucosal hematomas correlate with vessel friability caused by amyloid deposits of the vessel walls, which were also confirmed in histological examinations of the present case. Ulcers are thought to be secondary mucosal damage resulting from hematomas.

James et al. [12] revealed that nearly three-fourths $(12 / 17 ; 71 \%)$ of the patients with AL amyloidosis of the luminal GI tract had abnormal findings on endoscopic examination. Mucosal erosions or ulcerations $(6 / 17 ; 35 \%)$ and submucosal hematomas $(6 / 17 ; 35 \%)$ were the most common endoscopic findings. They reported the endoscopic finding of a submucosal hematoma as a distinctive finding for AL amyloid involvement of the luminal GI tract in the setting of GI bleeding. Physicians should consider underlying AL amyloidosis when detecting submucosal hematomas of the GI tract on endoscopic examination.

AL amyloidosis is largely a disease of the elderly that has been increasing in incidence as the population ages. Clonal proliferations of plasma cells, termed plasma cell dyscrasias, serve as the precursor state to AL amyloidosis. The concentration of immunoglobulin light chains is important; the long-term risk of developing AL amyloidosis in patients with MGUS is estimated to be $0.8 \%$ [13], whereas the risk associated with multiple myeloma has been estimated as high as $38 \%$ [14].

The treatment of AL amyloidosis includes myeloma-type chemotherapy and high-dose chemotherapy with hematopoietic stem cell transplantation. By suppressing the plasma cell clones, chemotherapy reduces the concentration of toxic light chains, which is necessary to improve organ function and prolong survival [15]. However, AL amyloidosis is not merely a hematologic malignancy; amyloid-related dysfunction of one or more organs determines survival and limits patient access to aggressive treatments. Therefore, treatment requires a riskadapted approach with dose reductions and schedule modifications of chemotherapy regimens and a close monitoring of hematologic and organ responses. Recently, novel chemotherapy agents have become available, and bortezomib-containing regimens have achieved high 
Fukui et al.: Colonic Findings of Amyloid Light-Chain Amyloidosis

hematologic response rates and can be effective treatments for severe cardiac AL amyloidosis [2]. Although this patient has not reported any symptoms and has not yet been examined for amyloid deposition in his cardiac tissue, his cardiac function has already decreased. After coronary artery stenting, his cardiac function is improving. Therefore, in the future, combination therapy with bortezomib, lenalidomide, and dexamethasone for MGUS is planned. Through the relatively early detection and treatment of his disorder, we hope to improve his prognosis.

In conclusion, this is a case report of systemic AL amyloidosis caused by MGUS, which was incidentally detected by colonoscopy. We describe characteristic and intriguing endoscopic findings of AL amyloidosis.

\section{Acknowledgements}

We would like to thank the Department of Hematology and Diagnostic Pathology of Kansai Medical University for their invaluable assistance in the case.

\section{Statement of Ethics}

The authors have no ethical conflicts to disclose. Informed consent was not obtained because the patient cannot be identified based on the presented data.

\section{Disclosure Statement}

The authors have no conflicts of interest to declare.

\section{Funding Sources}

This research did not receive any specific grant from funding agencies in the public, commercial, or not-for-profit sectors.

\section{Author Contributions}

Toshiro Fukui wrote this paper; all other members equally contributed to medical treatment. 
Fukui et al.: Colonic Findings of Amyloid Light-Chain Amyloidosis

\section{References}

1 Kyle RA, Gertz MA. Primary systemic amyloidosis: clinical and laboratory features in 474 cases. Semin Hematol. 1995 Jan;32(1):45-59.

2 Merlini G. CyBorD: stellar response rates in AL amyloidosis. Blood. 2012 May;119(19):4343-5.

3 Kumar SK, Gertz MA, Lacy MQ, Dingli D, Hayman SR, Buadi FK, et al. Recent improvements in survival in primary systemic amyloidosis and the importance of an early mortality risk score. Mayo Clin Proc. 2011 Jan;86(1):12-8.

4 Wechalekar AD, Gillmore JD, Hawkins PN. Systemic amyloidosis. Lancet. 2016 Jun;387(10038):2641-54.

5 Kyle RA, Therneau TM, Rajkumar SV, Larson DR, Plevak MF, Offord JR, et al. Prevalence of monoclonal gammopathy of undetermined significance. N Engl J Med. 2006 Mar;354(13):1362-9.

6 Kyle RA, Therneau TM, Rajkumar SV, Offord JR, Larson DR, Plevak MF, et al. A long-term study of prognosis in monoclonal gammopathy of undetermined significance. N Engl J Med. 2002 Feb;346(8):564-9.

7 Ebert EC, Nagar M. Gastrointestinal manifestations of amyloidosis. Am J Gastroenterol. 2008 Mar;103(3):776-87.

8 Tada S, Iida M, Yao T, Kawakubo K, Yao T, Okada M, et al. Endoscopic features in amyloidosis of the small intestine: clinical and morphologic differences between chemical types of amyloid protein. Gastrointest Endosc. 1994 Jan-Feb;40(1):45-50.

9 Kobayashi H, Tada S, Fuchigami T, Okuda Y, Takasugi K, Matsumoto T, et al. Secondary amyloidosis in patients with rheumatoid arthritis: diagnostic and prognostic value of gastroduodenal biopsy. Br J Rheumatol. 1996 Jan;35(1):44-9.

10 Hirata K, Sasaguri T, Kunoh M, Shibao K, Nagata N, Itoh H. Solitary "amyloid ulcer" localized in the sigmoid colon without evidence of systemic amyloidosis. Am J Gastroenterol. 1997 Feb;92(2):356-7.

11 Kyle RA, Rajkumar SV. Criteria for diagnosis, staging, risk stratification and response assessment of multiple myeloma. Leukemia. 2009 Jan;23(1):3-9.

12 James DG, Zuckerman GR, Sayuk GS, Wang HL, Prakash C: Clinical recognition of al type amyloidosis of the luminal gastrointestinal tract. Clin Gastroenterol Hepatol. 2007 May;5(5):582-8.

13 Pasqualetti P, Festuccia V, Collacciani A, Casale R. The natural history of monoclonal gammopathy of undetermined significance. A 5- to 20-year follow-up of 263 cases. Acta Haematol. 1997;97(3):174-9.

14 Desikan KR, Dhodapkar MV, Hough A, Waldron T, Jagannath S, Siegel D, et al. Incidence and impact of light chain associated (AL) amyloidosis on the prognosis of patients with multiple myeloma treated with autologous transplantation. Leuk Lymphoma. 1997 Oct;27(3-4):315-9.

15 Sattianayagam PT, Hawkins PN, Gillmore JD. Systemic amyloidosis and the gastrointestinal tract. Nat Rev Gastroenterol Hepatol. 2009 Oct;6(10):608-17. 


\section{Case Reports in Gastroenterology}

Case Rep Gastroenterol 2018;12:737-746
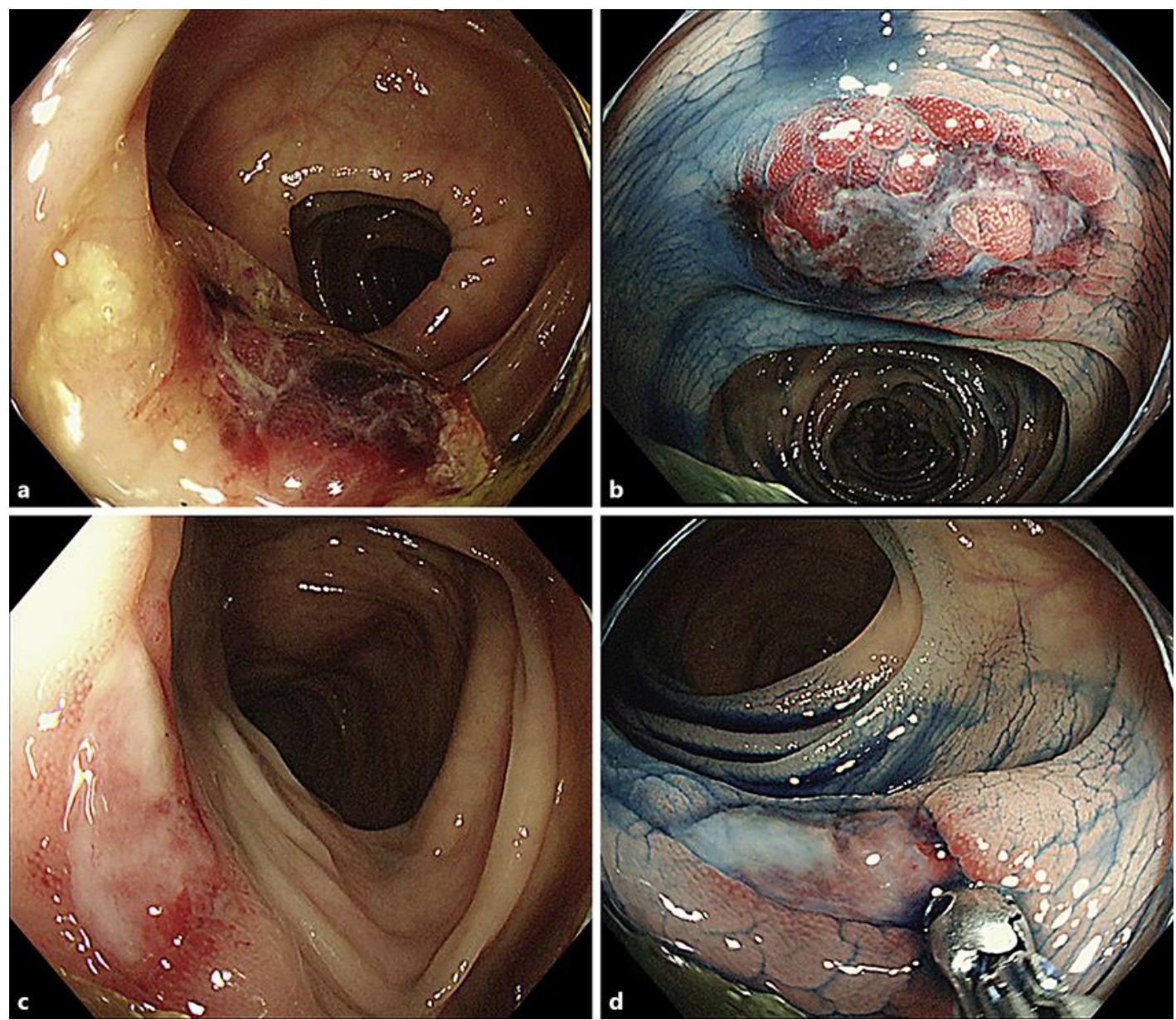

Fig. 1. Colonoscopic images of AL amyloidosis. A colonoscopy revealed two types of ulcerative lesions in the transverse colon; an irregularly shaped ulcer with submucosal hematoma (a, b) and a sharply marginated ulcer with slight submucosal hematoma $(\mathbf{c}, \mathbf{d})$. These lesions presumably reflect a time-dependent change of colonic findings of AL amyloidosis (b, $\mathbf{d}$ : with indigo carmine dye spraying). 


\section{Case Reports in Gastroenterology}

Case Rep Gastroenterol 2018;12:737-746

DOI: $10.1159 / 000494919$

(C) 2018 The Author(s). Published by S. Karger AG, Basel www.karger.com/crg

Fukui et al.: Colonic Findings of Amyloid Light-Chain Amyloidosis
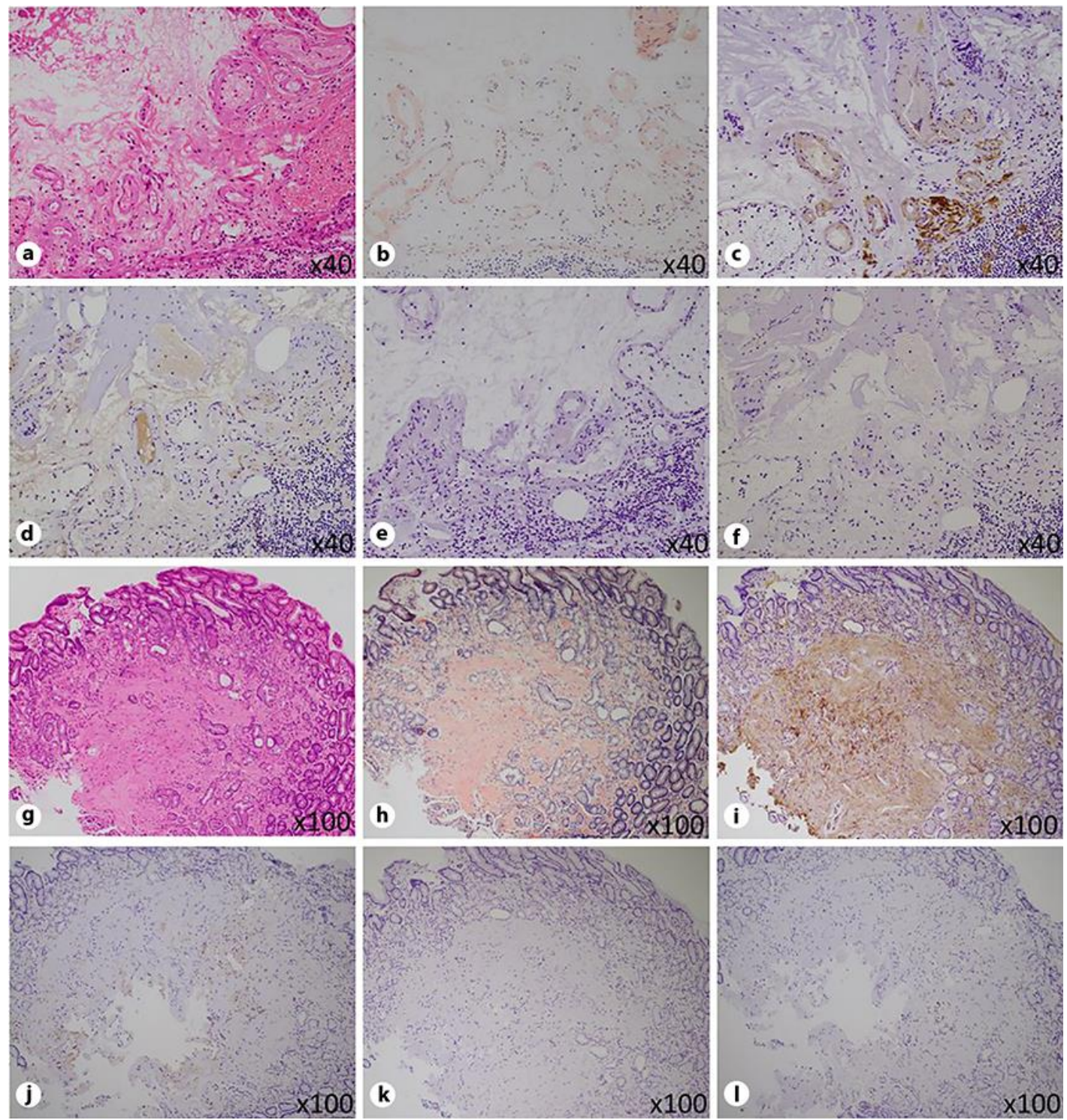

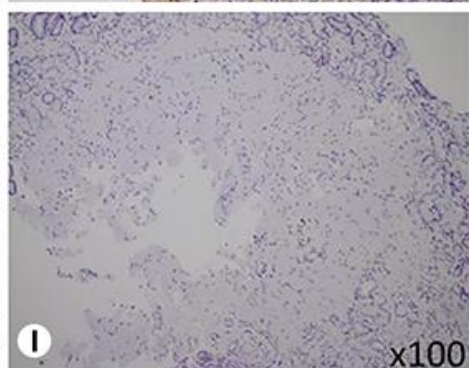

Fig. 2. Pathological findings of AL amyloidosis in the colon (a-f) and stomach ( $\mathbf{g}-\mathbf{I})$. Histological examinations revealed deposition of eosinophilic, homogeneous, and amorphous material in the submucosal blood vessel walls of the colon (a), which was positive for Congo red (b). Immunohistochemically, the deposits were positive for amyloid $P(\mathbf{c})$ and $\lambda$ light chain (d), and negative for AA (e) and $\kappa$ light chain (f). The same types of deposits were found in the mucosal stroma and blood vessel walls of the stomach (g), and were positive for Congo red (h), amyloid $P(\mathbf{i})$, and $\lambda$ light chain (j), and negative for AA (k) and $\kappa$ light chain (I). (a, $\mathbf{g}$ hematoxylin-eosin staining; b, h Congo red staining; $\mathbf{c}, \mathbf{i}$ anti-amyloid $\mathrm{P}$ staining; $\mathbf{d}, \mathbf{j}$ anti- $\lambda$ light chain staining; $\mathbf{e}, \mathbf{k}$ anti-AA staining; $\mathbf{f}, \mathbf{j}$ anti- $\mathrm{k}$ light chain staining.) 


\section{Case Reports in Gastroenterology}

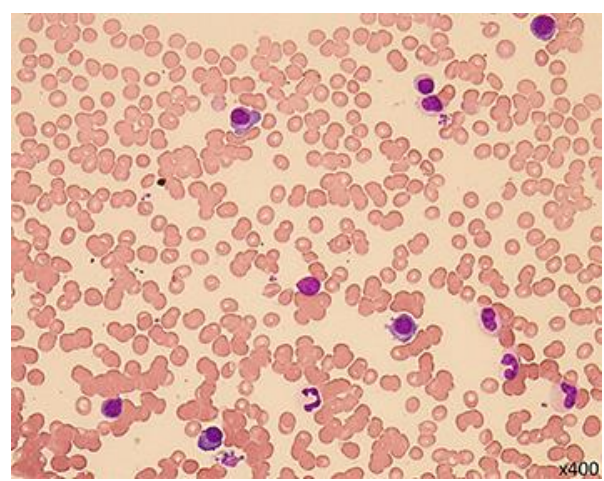

Fig. 3. Bone-marrow findings of MGUS. Bone marrow showed only mild plasmacytosis $(<10 \%$ of the nucleated cells). 
Table 1. The patient's laboratory data

\begin{tabular}{|c|c|c|c|}
\hline CBC & & Immunologic test & \\
\hline White blood cell & $51 \times 10^{2} / \mu \mathrm{L}$ & $\operatorname{IgG}$ & $1541 \mathrm{mg} / \mathrm{dL}$ \\
\hline Blast & $0 \%$ & $\operatorname{IgA}$ & $94 \mathrm{mg} / \mathrm{dL}$ \\
\hline Atypical lymphocyte & $0 \%$ & $\operatorname{IgM}$ & $26 \mathrm{mg} / \mathrm{dL}$ \\
\hline Red blood cell & $411 \times 10^{4} / \mu \mathrm{L}$ & $\operatorname{IgD}$ & $<1 \mathrm{mg} / \mathrm{dL}$ \\
\hline Hemoglobin & $12.1 \mathrm{~g} / \mathrm{dL}$ & CH50 & $57 \mathrm{U} / \mathrm{mL}$ \\
\hline Hematocrit & $36.4 \%$ & Antinuclear antibody & $(-)$ \\
\hline Platelet & $16.5 \times 10^{4} / \mu \mathrm{L}$ & Rheumatoid factor & $<5 \mathrm{IU} / \mathrm{mL}$ \\
\hline Coagulation test & & $\beta 2$-microglobulin & $2.2 \mathrm{mg} / \mathrm{L}$ \\
\hline $\mathrm{PT} \%$ & $103.3 \%$ & sIL-2R & $270 \mathrm{U} / \mathrm{mL}$ \\
\hline PT-INR & 0.98 & Serum protein fraction & \\
\hline APTT & $27.8 \mathrm{~s}$ & Albumin fraction & $64.8 \%(4.99 \mathrm{~g} / \mathrm{dL})$ \\
\hline Biochemistry & & $\alpha 1$-globulin fraction & $2.9 \%(0.22 \mathrm{~g} / \mathrm{dL})$ \\
\hline Total protein & $7.7 \mathrm{~g} / \mathrm{dL}$ & $\alpha 2$-globulin fraction & $9.6 \%(0.74 \mathrm{~g} / \mathrm{dL})$ \\
\hline Albumin & $5.0 \mathrm{~g} / \mathrm{dL}$ & $\beta$-globulin fraction & $6.2 \%(0.48 \mathrm{~g} / \mathrm{dL})$ \\
\hline $\mathrm{A} / \mathrm{G}$ ratio & 1.85 & $\gamma$-globulin fraction & $16.5 \%(1.27 \mathrm{~g} / \mathrm{dL})$ \\
\hline AST & $21 \mathrm{U} / \mathrm{L}$ & M-bow & $(+)$ \\
\hline ALT & $22 \mathrm{U} / \mathrm{L}$ & Immunoelectrophoresis & \\
\hline LDH & $120 \mathrm{U} / \mathrm{L}$ & IFE (M-protein) & $(+): \operatorname{IgG}-\lambda$ \\
\hline Alkaline phosphatase & $174 \mathrm{U} / \mathrm{L}$ & IFE (urinary BJP) & $(+): \lambda$ \\
\hline$\gamma$-GTP & $36 \mathrm{U} / \mathrm{L}$ & Serum-free light chain & \\
\hline Total bilirubin & $0.3 \mathrm{mg} / \mathrm{dL}$ & $\kappa$ chain & $12.7 \mathrm{mg} / \mathrm{L}$ \\
\hline Creatine kinase & $88 \mathrm{U} / \mathrm{L}$ & $\lambda$ chain & $168 \mathrm{mg} / \mathrm{L}$ \\
\hline Amylase & $68 \mathrm{U} / \mathrm{L}$ & $\kappa / \lambda$ & 0.076 \\
\hline Triglyceride & $399 \mathrm{mg} / \mathrm{dL}$ & BM examination & \\
\hline Total cholesterol & $126 \mathrm{mg} / \mathrm{dL}$ & Nucleated-cell count & $25000 / \mu \mathrm{L}$ \\
\hline Cholinesterase & $207 \mathrm{U} / \mathrm{L}$ & Myeloid/erythroid & 1.6 \\
\hline Creatinine & $0.91 \mathrm{mg} / \mathrm{dL}$ & Blast & $0.4 \%$ \\
\hline Blood urea nitrogen & $19 \mathrm{mg} / \mathrm{dL}$ & Promyelocyte & $0.5 \%$ \\
\hline Uric acid & $4.8 \mathrm{mg} / \mathrm{dL}$ & Myelocyte & $11.6 \%$ \\
\hline C-reactive protein & $0.118 \mathrm{mg} / \mathrm{dL}$ & Metamyelocyte & $3.5 \%$ \\
\hline $\mathrm{Fe}$ & $72 \mu \mathrm{g} / \mathrm{dL}$ & Plasma cell & $5.2 \%$ \\
\hline Ferritin & $113 \mathrm{ng} / \mathrm{mL}$ & G-banding (MM/PL) & NP \\
\hline Calcium & $9.8 \mathrm{mg} / \mathrm{dL}$ & & \\
\hline TSH & $8.28 \mu \mathrm{IU} / \mathrm{mL}$ & Urine test & \\
\hline Free thyroxin & $0.83 \mathrm{ng} / \mathrm{dL}$ & Protein & $(-)$ \\
\hline Hemoglobin A1c & $6.4 \%$ & Sugar & $(-)$ \\
\hline NT-proBNP & $999 \mathrm{pg} / \mathrm{mL}$ & Occult blood & $(-)$ \\
\hline
\end{tabular}

CBC, complete blood cell count; PT, prothrombin time; PT-INR, prothrombin time-international normalized ratio; APTT, activated partial thromboplastin time; $\mathrm{A} / \mathrm{G}$ ratio, albumin-globulin ratio; AST, aspartate aminotransferase; ALT, alanine aminotransferase; LDH, lactate dehydrogenase; $\gamma$-GTP, $\gamma$-glutamyl transpeptidase; TSH, thyroid-stimulating hormone; NT-proBNP, N-terminal pro-brain natriuretic peptide; CH50, 50\% hemolytic complement; sIL-2R, soluble interleukin-2 receptor; IFE, immunofixation electrophoresis; BJP, Bence-Jones protein; BM, bone marrow; MM, multiple myeloma; PL, plasmacytic leukemia; NP, not particular. 